\title{
Número de sección del tallo para la siembra del Pennisetum sp. "maralfalfa" y el rendimiento forrajero
}

Level of sectioning of the stem in the sowing of the Pennisetum sp. "Maralfalfa" in performance in Guayabal - Santa Maria

Rufino Maximo Maguiña Maza ${ }^{1}$, Edinson Pérez Díaz ${ }^{2}$

\section{RESUMEN}

Objetivo: determinar si el número de la sección del tallo para la siembra del Pennisetum sp. "maralfalfa", influyen en el establecimiento y rendimiento forrajero. Métodos: La variable Independiente fue el número de la sección: $1^{\circ}, 2^{\circ}$ y $3^{\circ}$; como variables dependientes fueron: número de yemas, número de tallos, altura $(\mathrm{cm})$ y rendimiento forrajero $(\mathrm{t} / \mathrm{ha})$. Resultados: En el número de yemas y altura de planta, se encontró una diferencia altamente significativa $(p<0.01)$ a favor de la $2^{\circ}$ y $3^{\circ}$ sección. En relación al número de tallos se encontró una diferencia altamente significativa $(p<0.01)$, a favor de la $3^{\circ}$ sección. Con relación al rendimiento de forraje se encontró diferencias altamente significativas $(p<0.01)$ a favor de la $3^{\circ}$ sección. Conclusión: El $3^{\circ}$ sección del tallo mejoró entre otras, el rendimiento de forrajes a la cosecha.

Palabras clave: Semilla vegetativa, Pennisetum, Siembra, Maralfalfa.

\section{ABSTRACT}

Objective: to determine whether the number of the stem section for planting Pennisetum $\mathrm{sp}$. "maralfalfa" influence the establishment and forage yield. Methods: the independent variable was the section number: 1st, 2nd and 3rd; the dependent variables were: number of buds, number of stems, height (cm) and forage yield ( $\mathrm{t} / \mathrm{ha}$ ). Results: in the number of yolks and plant height, a highly significant difference $(p<0.01)$ was found in favor of the 2 nd and 3rd section. In relation to the number of stems a highly significant difference was found $(p<0.01)$, in favor of the 3rd section. Regarding forage performance, highly significant differences $(p<0.01)$ were found in favor of the 3rd section. Conclusion: The 3rd section of the stem improved among others, the yield of forage harvest.

Keywords: Vegetative seed, Pennisetum, Sowing, Maralfalfa.

\footnotetext{
${ }_{2}^{1}$ Facultad de Ingeniería Agraria, Industrias Alimentarias y Ambiental. Universidad Nacional José Faustino Sánchez Carrión.

${ }^{2}$ Huacho, Perú. Ingeniero Zootecnista, Práctica Privada.
} 


\section{INTRODUCCIÓN}

En la plantación y establecimiento de las plantas forrajeras del género Pennisetum, por muy rústicas y agresivas que sean, requieren un tiempo determinado entre la siembra y el inicio de la producción. Esto dependerá entre muchas condiciones, desde la cosecha de la semilla, calidad de la misma, época de siembra, preparación del terreno; que implica una serie de operaciones agrícolas que en su conjunto representa un costo elevado (Ayala, 1990). La propagación de éste género de plantas forrajeras es a través de las semillas vegetativas, siendo éstas más viables que las semillas botánicas. Estas semillas, denominadas esquejes (Ayala, 1990) o estacas que consisten en trozos de tallos provenientes de plantas bien desarrollados con entrenudos que hayan completado su proceso de elongación a fin de que cuenten con yemas completamente desarrollados y con un alto nivel de carbohidratos solubles (Sierra, 2005). Estas semillas deben de ser trozados con tres nudos para asegurar la viabilidad ante el riesgo de contaminación con cualquier ente patógeno en los extremos de las estacas (Fauconnier y Bassereau 1975) y hay mayores respuestas de brotes en más de una yema en el periodo de establecimiento, asegurando mayores rendimientos forrajeros. En esta investigación se ha centrado en evaluar el establecimiento y el rendimiento forrajero utilizando diferentes secciones del tallo como semilla vegetativa para lograr una mayor productividad. Por lo que el objetivo de la investigación fue evaluar el número de la sección del tallo como semilla vegetativa de la "maralfalfa" en el rendimiento forrajero bajo las condiciones medioambientales del valle de Huaura.

\section{MATERIAL Y MÉTODOS}

El estudio se realizó en las áreas de cultivo del Establo Piamonte SAC, ubicado en Guayabal, distrito Santa María, provincia de Huaura. Utilizando un área de $300 \mathrm{~m}^{2}$, a $85 \mathrm{msnm}$ de altitud, localizado a latitud de $11^{\circ} 05^{\prime} 30^{\prime \prime}$ y longitud $77^{\circ} 34^{\prime} 23^{\prime \prime}$ sobre el meridiano de Greenwich. La temperatura máxima media en el distrito oscila entre $22^{\circ} \mathrm{C}$ en verano y $14^{\circ} \mathrm{C}$ en invierno. Según el análisis el suelo, es de característica arenoso franco con $p^{H}$ de 8,5 y una conductividad eléctrica de $0,46 \mathrm{mS} / \mathrm{cm}$. Tiene un contenido de materia orgánica de $0,70 \%$. Se utilizaron semillas vegetativas $(400$ esquejes) provenientes de plantas con 5 meses de crecimiento. Se realizaron las labores culturales para la siembra; la preparación del suelo, utilizando un arado vertedera a una profundidad de 30 a $40 \mathrm{~cm}$. Para la siembra se seleccionaron tallos bien formados, se seccionaron los tallos, separando las semillas vegetativas de tres nudos cada uno según nivel de seccionamiento. Se sembró cada estaca con inclinación de 20 a 30 grados, dos nudos bajo tierra y uno al ras del suelo. La separación entre surcos fue de $0,82 \mathrm{~cm}$ y la separación entre semillas de $0,90 \mathrm{~cm}$, aproximadamente. El control de malezas, se realizó manualmente durante todo el cultivo hasta la cosecha. Los riegos se realizaron con aguas de lavado de mandiles de establo y de canal de regadío una vez por semana. Cuando las plantas comenzaron a nacer se requirió menos cantidad de agua con la finalidad de mantener una humedad constante. En la fertilización se utilizaron aproximadamente 30 t/ha de estiércol de ganado bovino lechero. La cosecha se realizó a los 150 días.

La variable independiente evaluada fue el nivel de sección del tallo considerando la sección del tallo que incluye los tres primeros nudos del tallo cosechado, la sección del tallo del cuarto al sexto nudo, y la sección del tallo desde el séptimo al noveno nudo. Las variables dependientes fueron: el número de yemas a los 28 días $\left(\mathrm{N}^{\circ}\right)$, el número de tallos a la cosecha $\left(\mathrm{N}^{\circ}\right)$, altura del forraje a la cosecha $(\mathrm{cm})$ tomada a la altura del ápice del tallo, y el rendimiento de forraje a la cosecha (t/ha).

Se utilizó la técnica de la observación y medición para el levantamiento de datos. Esta información se registró en formatos elaborados con ese fin y el análisis estadístico se utilizó un diseño de bloques completos al azar. Los tratamientos $(t=3)$ fueron las secciones $1^{\circ}, 2^{\circ}$ y $3^{\circ}$. Los bloques $(b=4)$ correspondían a la ubicación de las parcelas, y la submuestra dentro de cada repetición, estaba constituida por treinta plantas.

\section{RESULTADOS}

El número de yemas a los veintiocho días, según el número de sección, puede apreciarse que la segunda y tercera sección favorecieron a un mayor número de yemas, comparado a la primera sección $(p<0,01$; Tabla 1). 
Tabla 1 Número de yemas en los esquejes de maralfalfa (28 días)

\begin{tabular}{lc}
\hline Sección & Yemas, $\mathbf{N}^{\circ}$ \\
\hline Primer & $3,98 \pm 0,12^{\mathrm{b}}$ \\
Segundo & $4,72 \pm 0,12^{\mathrm{a}}$ \\
Tercero & $5,02 \pm 0,12^{\mathrm{a}}$ \\
\hline${ }_{a, b}$ Letras distintas indican diferencia estadística $(p<0,01)$.
\end{tabular}

El número de tallos existentes a la cosecha, según al nivel de seccionamiento, se observa que la tercera sección fue mayor comparado a los demás $(p<0,01)$. Asimismo, la altura de la planta lograda a la cosecha, según el número de secciones, puede apreciarse que los secciones $2^{\circ}$ y $3^{\circ}$ favorecieron a una mayor altura comparado a la sección $3^{\circ}(p<0,01 ;$ Tabla 2$)$.

Tabla2. Número de tallos al primer corte en maralfalfa

\begin{tabular}{lcc}
\hline Sección & Tallos, $\mathbf{N}^{\mathbf{}}$ & Altura, $\mathbf{c m}$ \\
\hline Primer & $31,61 \pm 0,33^{\mathrm{b}}$ & $289,52 \pm 1,67^{\mathrm{b}}$ \\
Segundo & $32,64 \pm 0,33^{\mathrm{b}}$ & $296,07 \pm 1,67^{\mathrm{a}}$ \\
Tercero & $37,13 \pm 0,33^{\mathrm{a}}$ & $296,48 \pm 1,67^{\mathrm{a}}$ \\
\hline
\end{tabular}

${ }^{a, b}$ Letras distintas indican diferencia estadística $(p<0,01)$.

El rendimiento forrajero al primer corte según al número de secciones, se observa que la tercera sección obtuvo el mayor peso forrajero comparado a las otras dos secciones $(p<0,01)$.

Tabla 3. Rendimiento promedio de forraje al primer corte de la maralfalfa

\begin{tabular}{cc}
\hline Sección & Peso $(\mathbf{t} / \mathbf{h a})$ \\
\hline Primer & $123,70 \pm 0,88^{c}$ \\
Segundo & $130,10 \pm 0,88^{b}$ \\
Tercero & $137,13 \pm 0,88^{a}$ \\
\hline$a, b, c$ Letras distintas indican diferencia estadística $(p<0,01)$.
\end{tabular}

\section{DISCUSION}

El mayor número de yemas encontrado en la tercera sección, está de acuerdo con lo reportado por Ayala (1990) para King grass, y caña de azúcar (Núñez y Cruz, 2011), quienes mencionan que en esquejes jóvenes de seccionamientos intermedios y terminales producen mayor número de yemas, con mayor vigor germinativo, habiendo más azúcares reductores a este nivel (glucosa y fructuosa); que son sustancias que requiere la yema para alcanzar un adecuado desarrollo (Barrantes y Chaves, 2003). El similar número de yemas entre los dos seccionamientos puede deberse a que en estas secciones se almacenan mayor cantidad de reservas, principalmente en plantas jóvenes en estado de desarrollo vegetativo tardío.

El mayor número de tallos a la cosecha se explica por el mayor número de yemas encontrado a los 28 días y así también, lo menciona Fauconnier y Bassereau (1975). Similares resultados fueron reportados por Núñez y Cruz (2011) y Barrantes y Chaves (2003). 
La similar altura entre los dos niveles de seccionamientos puede deberse a que se tienen mayores números de yemas y mayor poder germinativo (Barrantes y Chaves, 2003).

El mayor número de yemas y tallos, explican el mayor peso del forraje, similar al obtenidos por Barrantes y Chaves (2003); Fauconnier y Bassereau (1975); Núñez y Cruz (2011) y Ayala (1990).

\section{REFERENCIAS BIBLIOGRAFICAS}

Ayala, J. (1990). Plantación y establecimiento. En: King grass. Plantación, establecimiento y manejo en Cuba. Ed. EDICA, Instituto de Ciencia Animal. La Habana. 34-37.

Barrantes, J. y Chaves, M. (2003) Efecto de la sección del tallo usado como semilla en la Producción agroindustrial de la caña de azúcar (Saccharum spp), cultivada en Pérez Zeledón, Costa Rica. Memoria. San José, Asociación de Técnicos Azucareros de Costa Rica (ATACORI), setiembre. p: 179-182.

Fauconnier, R. y Bassereau, D (1975) Caña de azúcar. Editorial Blume Barcelona. España $.433 \mathrm{pp}$.
Herrera, R. S. (1990). Introducción y características botánicas; En: King grass Plantación, establecimiento y manejo en Cuba. Ed. EDICA. Instituto de Ciencia Animal, La Habana, Cuba. 18.

Núñez, O y Cruz, R. (2011) Germinación y desarrollo de la caña de azúcar sembrada con esquejes de diferentes secciones del tallo y edades de corte. II Congreso Ecuatoriano de la Caña de Azúcar y sus derivados.

http://www.aeta.org.ec/2do\%20congres o\%20cana/art_campo/NUNEZ,\%20se milla.pdf

Sierra, J. (2005). Fundamentos para el establecimiento de pasturas y cultivos forrajeros. Universidad de Antioquia. Colombia. P: 144-145.

\section{Correo electrónico:}

rufinomaximo@gmail.com

Revisión de pares:

Recibido: 22-04-2019

Aceptado: 24-06-2019 